(2) Open Access Full Text Article

\title{
Fentanyl-induced respiratory depression is attenuated in pregnant patients
}

\author{
This article was published in the following Dove Press journal: \\ Drug Design, Development and Therapy \\ Number of times this article has been viewed
}

\section{Xiaofei Cao* \\ Shijiang Liu* \\ Jie Sun \\ Min Yu \\ Yin Fang \\ Zhengnian Ding}

Department of Anesthesiology, The First Affiliated Hospital of Nanjing Medical University, Nanjing, Jiangsu Province, China

*These authors contributed equally to this work
Correspondence: Zhengnian Ding Department of Anesthesiology, The First Affiliated Hospital of Nanjing Medical University, 300 Guangzhou Road, Nanjing, Jiangsu Province 210029, China Tel +862568136760

Email zhengnianding@yeah.net

\begin{abstract}
Background: Respiratory depression is a complication of intravenous fentanyl administration. The effect of pregnancy on respiratory depression following opioid administration is unclear. This study investigated the effect of pregnancy on fentanyl-induced respiratory depression.

Patients and methods: Female patients were divided into three groups ( $\mathrm{n}=20$ per group): control group (non-pregnant and scheduled for laparoscopic surgery), early pregnancy group (pregnant for 45-60 days and scheduled for abortion), and postpartum group (5-7 days postpartum scheduled for complete curettage of uterine cavity). All patients received an intravenous infusion of fentanyl $2 \mu \mathrm{g} / \mathrm{kg}$. Respiratory rate (RR), end-tidal pressure of carbon dioxide $\left(\mathrm{P}_{\mathrm{ET}} \mathrm{CO}_{2}\right)$, and pulse oxygen saturation $\left(\mathrm{SpO}_{2}\right)$ were recorded continuously from just before fentanyl infusion to $15 \mathrm{~min}$ after commencing infusion. Plasma levels of progesterone were measured.

Results: $\mathrm{SpO}_{2}$ levels in the early pregnancy and postpartum groups were significantly higher and the levels of RR and $\mathrm{P}_{\mathrm{ET}} \mathrm{CO}_{2}$ were significantly lower than the control group. RR and $\mathrm{SpO}_{2}$ levels were significantly decreased in all groups, whereas $\mathrm{P}_{\mathrm{ET}} \mathrm{CO}_{2}$ was significantly increased after fentanyl infusion. The rates of $\mathrm{RR}$ increase and $\mathrm{SpO}_{2}$ decrease were significantly faster in the control group than in the other groups. The lowest $\mathrm{SpO}_{2}$ after intravenous fentanyl administration was significantly positively correlated with plasma progesterone levels.
\end{abstract}

Conclusion: Pregnancy improves fentanyl-induced respiratory depression, which may be associated with the increased levels of plasma progesterone.

Keywords: fentanyl, pregnancy, respiratory depression, progesterone

\section{Introduction}

Opioids are widely used in postoperative analgesia. However, their use can cause severe adverse outcomes, such as respiratory depression. Pregnancy influences many aspects of the maternal physiological and pathological processes. Of particular interest to this study, dosages of narcotic drugs are usually less for pregnant women with hyperventilation during general anesthesia. ${ }^{1}$ However, the effect of pregnancy on respiratory depression following opioid administration is unclear. To address this question, we examined the respiratory response to intravenous fentanyl in non-pregnant, early pregnant, and postpartum females.

\section{Patients and methods}

\section{Patient enrollment}

The study was approved by the ethics and research committee of Nanjing Medical University (Nanjing, China), and informed consent was signed according to the Declaration of Helsinki. Sixty female patients aged 20-35 years weighting $47-70 \mathrm{~kg}$ and body mass index (BMI) 18-30 with American Society of Anesthesiologists (ASA) Grade I-II were enrolled. Exclusion criteria included allergies to opioids, history of 
alcohol or drug abuse, history of sedative-hypnotic and narcotic drugs, and history of sleep apnea or respiratory complications. Patients who had taken opioids or analgesics before surgery were also excluded. Twenty were non-pregnant (within 15 days before menstruation) and were scheduled for laparoscopic surgery due to infertility (control group). Twenty patients were at 45-60 days of pregnancy and were scheduled for abortion (early pregnancy group). Twenty patients were 5-7 days postpartum and were scheduled for complete curettage of uterine cavity because of placental remnants (postpartum group).

\section{Study protocol}

No premedication was given before the surgery. After entering the operation room, all patients were placed supine with inhalation of room air. Lactated Ringer solution was infused at a rate of $8 \mathrm{~mL} / \mathrm{kg} / \mathrm{h}$. Patient's nasal patency was confirmed. An end-tidal $\mathrm{CO}_{2}$ sampling tube was inserted $2 \mathrm{~cm}$ into the nasal cavity to measure end-tidal pressure of carbon dioxide $\left(\mathrm{P}_{\mathrm{ET}} \mathrm{CO}_{2}\right)$. Respiratory rate $(\mathrm{RR}), \mathrm{P}_{\mathrm{ET}} \mathrm{CO}_{2}$, and pulse oxygen saturation $\left(\mathrm{SpO}_{2}\right)$ were measured continuously using a Mindray PM9000 monitor (Mindray Inc., Shenzhen, China). Thereafter, $0.1 \mathrm{mg} / 2 \mathrm{~mL}$ fentanyl citrate (Yichang Renfu Inc., Yichang, China) was diluted to $10 \mathrm{~mL}$ with normal saline and infused into the cubital vein at a rate of $1 \mathrm{~mL} / 3 \mathrm{~s}$ with a total dose of $2 \mu \mathrm{g} / \mathrm{kg}$ after being completely anesthetized using only nasal breathing. The entire surgery was successful without any interruption, and the status of the patients was closely monitored. The patients remained undisturbed and breathed quietly through the nose with close monitoring. If the $\mathrm{SpO}_{2}$ was $\leq 80 \%$, the patient might wake up. In that case, they were instructed to take deep breaths to increase the $\mathrm{SpO}_{2}$ level. Controlled respiration was given by breathing mask to patients in the event of severe hypoxia.

\section{Measurements}

Three milliliters of blood was collected from the peripheral vein before infusion with Lactated Ringer solution. Serum was isolated for measurement of progesterone levels by microparticle chemical luminescence radioimmunoassay (Beckman Coulter Inc., Pasadena, CA, USA). RR, $\mathrm{SpO}_{2}$, and $\mathrm{P}_{\mathrm{ET}} \mathrm{CO}_{2}$ were recorded during a quiet period after the patients had entered the operating theater and 1-15 min after intravenous fentanyl was administered.

\section{Statistical analyses}

Data are presented as mean \pm standard deviation (SD). Groups were compared using one-way analysis of variance analysis (ANOVA) followed by Tukey's post hoc test, as appropriate with SPSS 17.0 software (SPSS Inc., Chicago, IL, USA). The correlation between two groups was analyzed. Statistical significance was set at $P<0.05$.

\section{Results}

\section{Pregnancy attenuates RR decrease following fentanyl treatment}

RR determined at different times in the three groups decreased following fentanyl administration, compared with their respective baseline levels ( $0 \mathrm{~min}$ ) (Table $1 \mathrm{~A}$ and Figure $1 \mathrm{~A}-\mathrm{C})$. The lowest RR was observed at $6 \mathrm{~min}$ in the non-pregnancy group, at $7 \mathrm{~min}$ in the early pregnancy group and at $8 \mathrm{~min}$ in the postpartum group. RR gradually returned toward baseline. However, the levels at $15 \mathrm{~min}$ in all three groups were still significantly lower than their baseline levels.

The rate of decrease of RR from baseline to the trough levels was compared among three groups. The RR decrease rates at 6,7 , and 8 min following fentanyl administration showed no significant difference among the three groups (Table 1B and Figure 1D).

The RR levels were compared between three groups at each measured time point. Baseline RR was significantly higher in the postpartum group than in the non-pregnancy group. Importantly, the RR levels were significantly higher in the early pregnancy and postpartum groups at 1, 2, 3, and 5 min following fentanyl administration compared with time-matched non-pregnancy group measurements (Table 1A and Figure 1E).

Table IA Respiratory rate (bpm) in various time points

\begin{tabular}{llll}
\hline Time & $\begin{array}{l}\text { Non-pregnancy } \\
(\mathbf{n}=\mathbf{2 0})\end{array}$ & $\begin{array}{l}\text { Early pregnancy } \\
(\mathbf{n}=\mathbf{2 0})\end{array}$ & $\begin{array}{l}\text { Postpartum } \\
(\mathbf{n}=\mathbf{2 0})\end{array}$ \\
\hline $0 \mathrm{~min}$ & $18.30 \pm 2.34$ & $19.65 \pm 3.22$ & $20.90 \pm 3.00^{*}$ \\
$1 \mathrm{~min}$ & $16.60 \pm 2.54$ & $18.35 \pm 3.15$ & $20.80 \pm 2.78^{*}$ \\
$2 \mathrm{~min}$ & $15.20 \pm 2.24$ & $17.40 \pm 3.50^{*}$ & $18.40 \pm 1.23^{*}$ \\
$3 \mathrm{~min}$ & $13.20 \pm 1.74$ & $16.10 \pm 2.88^{*}$ & $17.10 \pm 1.74^{*}$ \\
$4 \mathrm{~min}$ & $12.50 \pm 2.21$ & $15.40 \pm 2.80^{*}$ & $16.30 \pm 1.95^{*}$ \\
$5 \mathrm{~min}$ & $12.70 \pm 1.69$ & $14.60 \pm 3.05^{*}$ & $14.60 \pm 1.73^{*}$ \\
$6 \mathrm{~min}$ & $11.85 \pm 1.84$ & $13.95 \pm 3.20^{\#}$ & $14.60 \pm 2.39^{*}$ \\
$7 \mathrm{~min}$ & $11.85 \pm 1.81$ & $13.45 \pm 2.70^{\#}$ & $13.95 \pm 1.57^{*}$ \\
$8 \mathrm{~min}$ & $12.00 \pm 2.15$ & $14.10 \pm 2.61^{*}$ & $13.30 \pm 1.49$ \\
$9 \mathrm{~min}$ & $12.50 \pm 2.48$ & $13.85 \pm 2.13$ & $13.40 \pm 1.90$ \\
$10 \mathrm{~min}$ & $12.90 \pm 2.69$ & $14.30 \pm 1.92$ & $13.40 \pm 2.60$ \\
$11 \mathrm{~min}$ & $13.30 \pm 2.00$ & $13.95 \pm 1.76$ & $14.50 \pm 3.14$ \\
$12 \mathrm{~min}$ & $13.00 \pm 2.34$ & $14.10 \pm 1.71$ & $14.10 \pm 3.02$ \\
$13 \mathrm{~min}$ & $13.20 \pm 1.82$ & $14.05 \pm 1.64$ & $14.35 \pm 2.89$ \\
$14 \mathrm{~min}$ & $13.25 \pm 2.02$ & $14.15 \pm 1.53$ & $14.45 \pm 2.95$ \\
$15 \mathrm{~min}$ & $13.95 \pm 1.91$ & $14.20 \pm 1.24$ & $14.95 \pm 2.44$ \\
\hline
\end{tabular}

Note: $* P<0.01$ (vs non-pregnancy group) and ${ }^{*} P<0.05$ (vs non-pregnancy group). Data shown as mean \pm SD. 

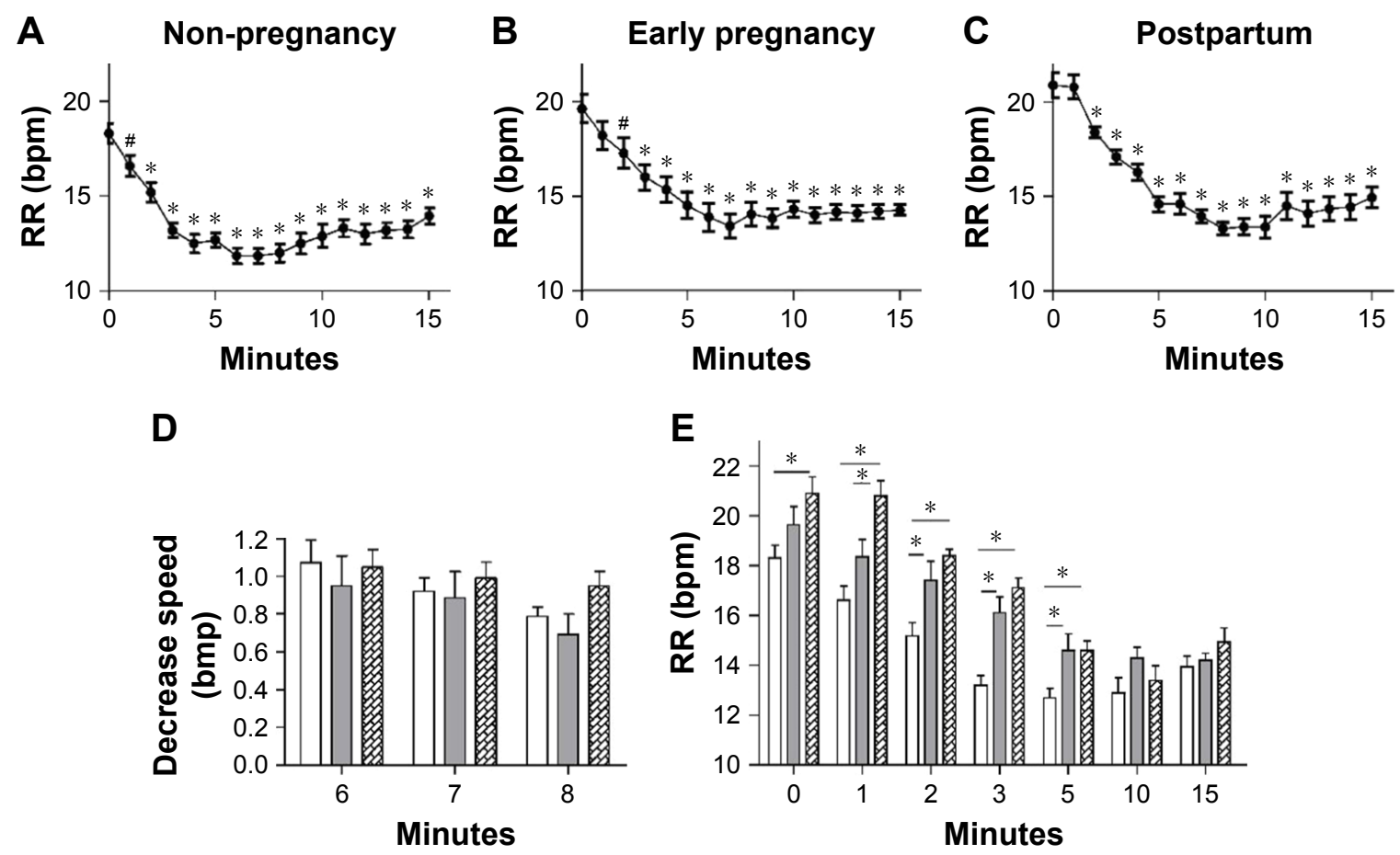

$\square$ Non-pregnancy $\square$ Early pregnancy $\square 0 x$ Postpartum

Figure I Pregnancy attenuates the fentanyl-induced decrease in RR.

Notes: RR was recorded immediately before and after fentanyl infusion (A-C). The decrease rate of RR from baseline to the trough levels (at 6 min for the non-pregnancy group, 7 min for the early pregnancy group and $8 \mathrm{~min}$ for the postpartum group) was calculated and compared (D). The levels of RR in all three groups at representative time points are also shown (E). $* P<0.01, \# P<0.05, n=20$ per group.

Abbreviation: $\mathrm{RR}$, respiratory rate.

\section{Pregnancy attenuates $\mathrm{P}_{E T} \mathrm{CO}_{2}$ increase following fentanyl treatment}

Table 2A displays $\mathrm{P}_{\mathrm{ET}} \mathrm{CO}_{2}$ determined at different times in the three groups. $\mathrm{P}_{\mathrm{ET}} \mathrm{CO}_{2}$ levels were increased in all the three groups following fentanyl administration compared with their baseline levels ( 0 min) (Figure 2A-C). The $\mathrm{P}_{\mathrm{ET}} \mathrm{CO}_{2}$ levels then gradually returned toward the baseline. However, the levels at 15 min after fentanyl administration in all three groups were still significantly greater than each baseline level.

The rate of increase of $\mathrm{P}_{\mathrm{ET}} \mathrm{CO}_{2}$ from baseline to the peak levels was compared in the three groups (Table 2B). The increase rate of $\mathrm{P}_{\mathrm{ET}} \mathrm{CO}_{2} 7$ min following fentanyl administration was not significantly different among the three groups (Figure 2D). However, the increase rate of $\mathrm{P}_{\mathrm{ET}} \mathrm{CO}_{2} 9$ min following fentanyl administration was significantly attenuated

Table IB Decrease rate of RR (bpm/min) among three groups

\begin{tabular}{llll}
\hline Time & $\begin{array}{l}\text { Non-pregnancy } \\
(\mathbf{n}=\mathbf{2 0})\end{array}$ & $\begin{array}{l}\text { Early pregnancy } \\
(\mathbf{n}=\mathbf{2 0})\end{array}$ & $\begin{array}{l}\text { Postpartum } \\
(\mathbf{n}=\mathbf{2 0})\end{array}$ \\
\hline $6 \mathrm{~min}$ & $1.08 \pm 0.53$ & $0.95 \pm 0.72^{*}$ & $1.05 \pm 0.42^{*}$ \\
$7 \mathrm{~min}$ & $0.92 \pm 0.32$ & $0.89 \pm 0.63^{*}$ & $0.99 \pm 0.38^{*}$ \\
$8 \mathrm{~min}$ & $0.79 \pm 0.22$ & $0.69 \pm 0.47^{*}$ & $0.95 \pm 0.35^{*}$ \\
\hline
\end{tabular}

Note: $* P>0.05$ (vs non-pregnancy group).

Abbreviation: RR, respiratory rate. by $39.5 \%(0.51 \pm 0.20$ vs $0.84 \pm 0.32 ; P<0.01)$ in the postpartum group compared with the non-pregnancy group.

Also, we compared $\mathrm{P}_{\mathrm{ET}} \mathrm{CO}_{2}$ levels between three groups at each time point. $\mathrm{P}_{\mathrm{ET}} \mathrm{CO}_{2}$ levels at baseline were significantly lower in the early pregnancy and postpartum groups than in

Table 2A End-tidal pressure of carbon dioxide $(\mathrm{mmHg})$ in various time points

\begin{tabular}{llll}
\hline Time & $\begin{array}{l}\text { Non-pregnancy } \\
(\mathbf{n}=\mathbf{2 0})\end{array}$ & $\begin{array}{l}\text { Early pregnancy } \\
(\mathbf{n}=\mathbf{2 0})\end{array}$ & $\begin{array}{l}\text { Postpartum } \\
(\mathbf{n}=\mathbf{2 0})\end{array}$ \\
\hline $0 \mathrm{~min}$ & $32.10 \pm 2.05$ & $29.55 \pm 2.86^{*}$ & $30.20 \pm 2.24^{*}$ \\
$1 \mathrm{~min}$ & $32.70 \pm 2.11$ & $30.55 \pm 2.84^{*}$ & $31.05 \pm 2.09^{\#}$ \\
$2 \mathrm{~min}$ & $32.45 \pm 2.56$ & $32.00 \pm 3.15$ & $32.55 \pm 1.93$ \\
$3 \mathrm{~min}$ & $34.15 \pm 3.10$ & $32.85 \pm 3.72$ & $33.10 \pm 1.62^{*}$ \\
$4 \mathrm{~min}$ & $35.25 \pm 3.08$ & $33.35 \pm 4.51$ & $33.30 \pm 2.74$ \\
$5 \mathrm{~min}$ & $37.10 \pm 4.12$ & $34.35 \pm 5.04^{\#}$ & $34.05 \pm 2.24^{\#}$ \\
$6 \mathrm{~min}$ & $38.40 \pm 3.32$ & $35.65 \pm 4.27^{\#}$ & $34.95 \pm 2.37^{*}$ \\
$7 \mathrm{~min}$ & $38.50 \pm 3.19$ & $36.05 \pm 4.0 I^{\#}$ & $35.60 \pm 1.85^{\#}$ \\
$8 \mathrm{~min}$ & $39.05 \pm 2.89$ & $35.70 \pm 3.5 I^{*}$ & $35.20 \pm 1.58^{*}$ \\
$9 \mathrm{~min}$ & $39.70 \pm 3.13$ & $35.50 \pm 3.59^{*}$ & $34.80 \pm 0.95^{*}$ \\
$10 \mathrm{~min}$ & $39.45 \pm 3.22$ & $35.40 \pm 3.50^{*}$ & $35.20 \pm 1.20^{*}$ \\
$11 \mathrm{~min}$ & $38.70 \pm 3.20$ & $35.10 \pm 3.26^{*}$ & $34.25 \pm 1.21^{*}$ \\
$12 \mathrm{~min}$ & $38.35 \pm 3.07$ & $34.65 \pm 3.30^{*}$ & $33.80 \pm 1.15^{*}$ \\
$13 \mathrm{~min}$ & $38.90 \pm 3.52$ & $34.00 \pm 2.62^{*}$ & $33.30 \pm 1.56^{*}$ \\
$14 \mathrm{~min}$ & $38.85 \pm 3.07$ & $34.35 \pm 2.68^{*}$ & $33.45 \pm 1.10^{*}$ \\
$15 \mathrm{~min}$ & $38.50 \pm 2.86$ & $34.25 \pm 2.6 I^{*}$ & $33.55 \pm 1.28^{*}$ \\
\hline
\end{tabular}

Note: $* P<0.01$ (vs non-pregnancy group) and $\# P<0.05$ (vs non-pregnancy group). 


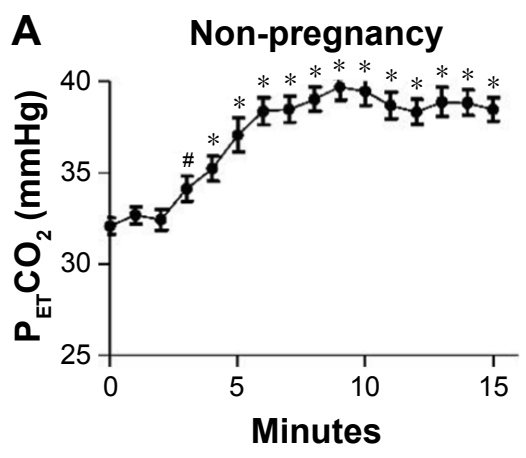

D

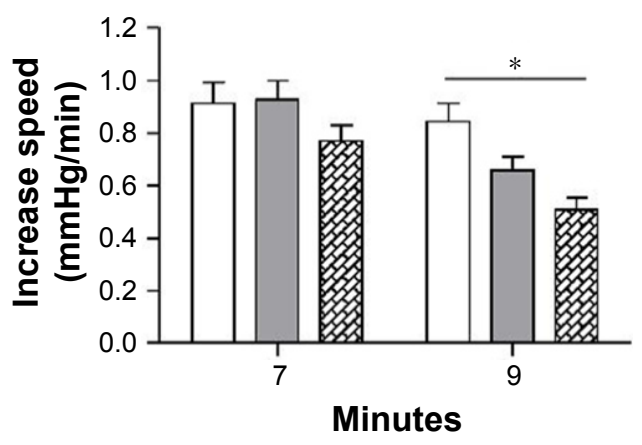

B Early pregnancy

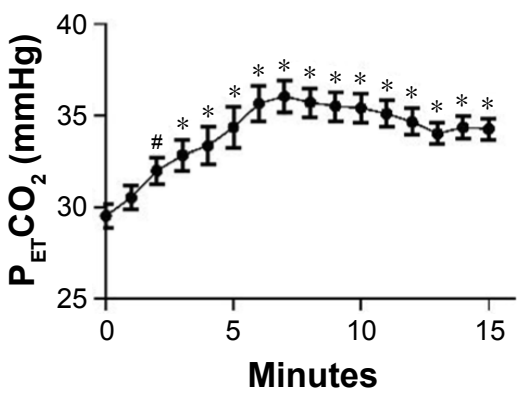

C Postpartum

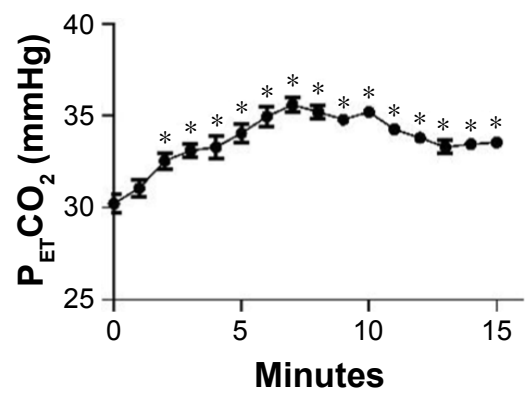

E

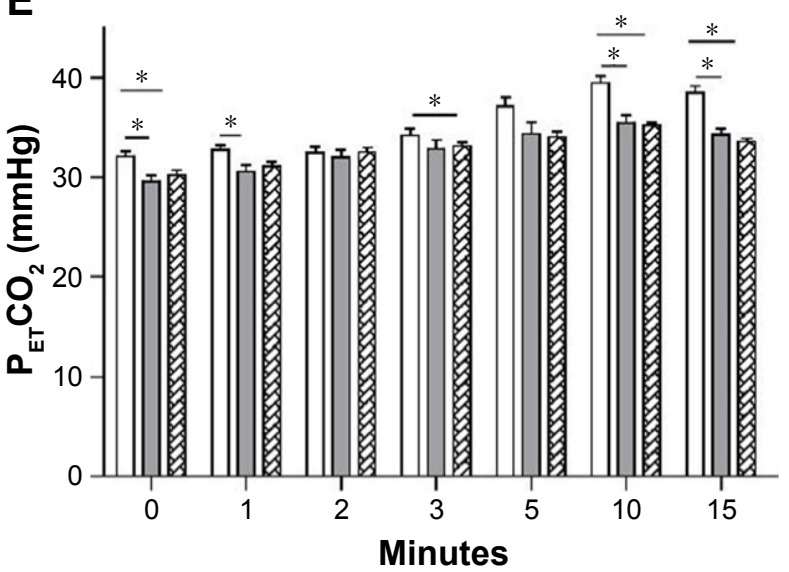

$\square$ Non-pregnancy $\square$ Early pregnancy $\square$ Postpartum

Figure 2 Pregnancy attenuates the fentanyl-induced increase in $\mathrm{P}_{\mathrm{ET}} \mathrm{CO}_{2}$.

Notes: $\mathrm{P}_{\mathrm{ET}} \mathrm{CO}_{2}$ levels were recorded immediately before and after fentanyl infusion (A-C). The increase rate of $\mathrm{P}_{\mathrm{ET}} \mathrm{CO}_{2}$ from baseline to the valley levels (at 9 min for the non-pregnancy group and 7 min for both early pregnancy and postpartum groups) was calculated and compared $(\mathbf{D})$. The levels of $P_{E T} C O_{2}$ in all three groups at representative time points are also shown $(\mathrm{E}) .{ }^{*} \mathrm{P}<0.0 \mathrm{I},{ }^{*} \mathrm{P}<0.05, \mathrm{n}=20$ per group.

Abbreviation: $\mathrm{P}_{\mathrm{ET}} \mathrm{CO}_{2}$, end-tidal pressure of carbon dioxide.

the non-pregnancy group. Importantly, the $\mathrm{P}_{\mathrm{ET}} \mathrm{CO}_{2}$ levels were significantly lower in the early pregnancy group at 1,10 and $15 \mathrm{~min}$ and in the postpartum group at 3,10 and $15 \mathrm{~min}$ than in the time-matched non-pregnancy group measurements (Table 2A and Figure 2E).

\section{Pregnancy attenuates $\mathrm{SpO}_{2}$ decline following fentanyl treatment}

Table 3A presents measurements of $\mathrm{SpO}_{2}$ at different times in the three groups. $\mathrm{SpO}_{2}$ levels decreased rapidly in the three

Table 2B Increase rate of $\mathrm{P}_{\mathrm{ET}} \mathrm{CO}_{2}(\mathrm{mmHg} / \mathrm{min})$ among three groups

\begin{tabular}{llll}
\hline Time & $\begin{array}{l}\text { Non-pregnancy } \\
(\mathbf{n}=\mathbf{2 0 )}\end{array}$ & $\begin{array}{l}\text { Early pregnancy } \\
(\mathbf{n}=\mathbf{2 0})\end{array}$ & $\begin{array}{l}\text { Postpartum } \\
(\mathbf{n}=\mathbf{2 0 )}\end{array}$ \\
\hline 7 min & $0.91 \pm 0.35$ & $0.93 \pm 0.33$ & $0.77 \pm 0.27$ \\
9 min & $0.84 \pm 0.32$ & $0.66 \pm 0.22^{\#}$ & $0.5 I \pm 0.20^{*}$ \\
\hline Note: $* P<0.0 I$ (vs non-pregnancy group) and $\# P<0.05$ (vs non-pregnancy group). \\
Abbreviation: $\mathrm{P}_{\mathrm{ET}} \mathrm{CO}_{2}$, end-tidal pressure of carbon dioxide.
\end{tabular}

Table 3A Pulse oxygen saturation (\%) in various time points

\begin{tabular}{llll}
\hline Time & $\begin{array}{l}\text { Non-pregnancy } \\
(\mathbf{n}=\mathbf{2 0})\end{array}$ & $\begin{array}{l}\text { Early pregnancy } \\
(\mathbf{n}=\mathbf{2 0})\end{array}$ & $\begin{array}{l}\text { Postpartum } \\
(\mathbf{n}=\mathbf{2 0})\end{array}$ \\
\hline $0 \mathrm{~min}$ & $97.45 \pm 1.54$ & $98.60 \pm 0.94^{*}$ & $97.50 \pm 1.05$ \\
$1 \mathrm{~min}$ & $97.20 \pm 1.77$ & $98.30 \pm 1.03^{*}$ & $96.60 \pm 0.68$ \\
$2 \mathrm{~min}$ & $95.70 \pm 2.68$ & $97.40 \pm 1.14^{*}$ & $95.30 \pm 1.78$ \\
$3 \mathrm{~min}$ & $94.45 \pm 2.91$ & $96.40 \pm 1.90^{*}$ & $94.60 \pm 1.79$ \\
$4 \mathrm{~min}$ & $91.40 \pm 3.32$ & $94.75 \pm 2.90^{*}$ & $94.25 \pm 2.40^{*}$ \\
$5 \mathrm{~min}$ & $89.20 \pm 3.68$ & $94.05 \pm 3.43^{*}$ & $93.65 \pm 2.60^{*}$ \\
$6 \mathrm{~min}$ & $88.25 \pm 3.78$ & $93.75 \pm 3.45^{*}$ & $93.05 \pm 2.3 I^{*}$ \\
$7 \mathrm{~min}$ & $87.95 \pm 2.67$ & $93.60 \pm 3.32^{*}$ & $92.85 \pm 1.93^{*}$ \\
$8 \mathrm{~min}$ & $87.75 \pm 1.92$ & $94.40 \pm 2.11^{*}$ & $93.10 \pm 2.13^{*}$ \\
$9 \mathrm{~min}$ & $88.80 \pm 1.77$ & $94.50 \pm 1.96^{*}$ & $93.20 \pm 1.99^{*}$ \\
$10 \mathrm{~min}$ & $88.85 \pm 1.66$ & $95.20 \pm 1.82^{*}$ & $93.30 \pm 2.1 I^{*}$ \\
$11 \mathrm{~min}$ & $91.30 \pm 1.49$ & $95.80 \pm 1.24 *$ & $94.25 \pm 1.94^{*}$ \\
$12 \mathrm{~min}$ & $92.75 \pm 1.25$ & $96.10 \pm 1.4 I^{*}$ & $94.65 \pm 2.06^{*}$ \\
$13 \mathrm{~min}$ & $93.10 \pm 0.91$ & $96.05 \pm 1.19 *$ & $94.65 \pm 1.79 *$ \\
$14 \mathrm{~min}$ & $93.75 \pm 0.79$ & $95.85 \pm 0.8 I^{*}$ & $95.25 \pm 1.37^{*}$ \\
$15 \mathrm{~min}$ & $94.60 \pm 0.50$ & $96.20 \pm 0.95^{*}$ & $95.05 \pm 1.10$ \\
\hline
\end{tabular}

Note: $* P<0.01$ (vs non-pregnancy group). 


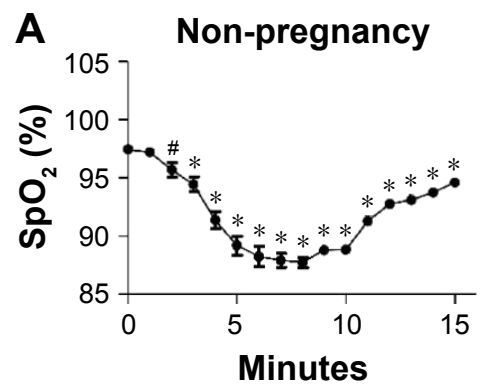

D

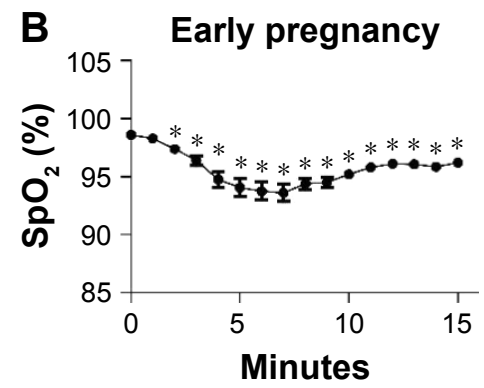

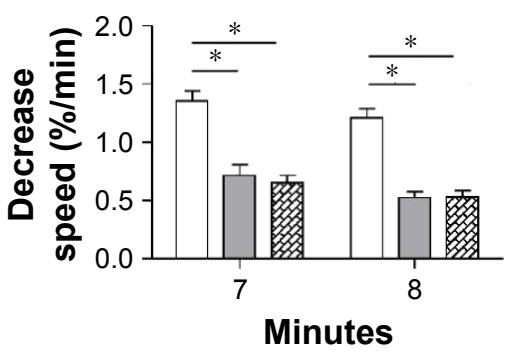
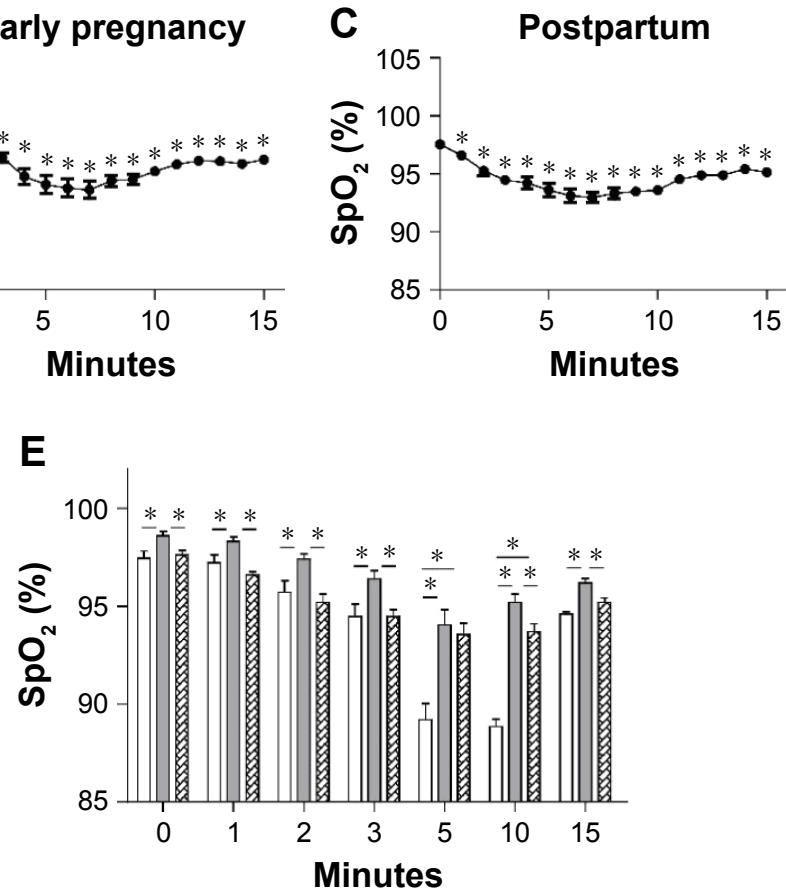

$\square$ Non-pregnancy $\square$ Early pregnancy ख Postpartum

Figure 3 Pregnancy attenuates the fentanyl-induced decrease in $\mathrm{SpO}_{2}$.

Notes: $\mathrm{SpO}_{2}$ was recorded immediately before and after fentanyl infusion $(\mathbf{A}-\mathbf{C})$. The decrease rate of $\mathrm{SpO}_{2}$ from baseline to the valley levels (at 8 min for the non-pregnancy group and $7 \mathrm{~min}$ for both early pregnancy and postpartum groups) was calculated and compared (D). The levels of $\mathrm{SpO}_{2}$ in all three groups at representative time points are also shown (E). $* P<0.01,{ }^{*} P<0.05, n=20$ per group.

Abbreviation: $\mathrm{SpO}_{2}$, pulse oxygen saturation.

groups following fentanyl administration compared with their respective baseline levels ( 0 min) (Figure $3 \mathrm{~A}-\mathrm{C})$. The lowest level of $\mathrm{SpO}_{2}$ was observed at $8 \mathrm{~min}$ in the non-pregnancy group and at $7 \mathrm{~min}$ in both the early pregnancy and postpartum groups following fentanyl administration. $\mathrm{SpO}_{2}$ levels thereafter gradually returned toward the baseline. However, the levels at $15 \mathrm{~min}$ after fentanyl administration in all three groups were still significantly lower than each baseline level.

The rate of decrease of $\mathrm{SpO}_{2}$ from baseline to the lowest levels was compared in the three groups (Table 3B). The decrease in the non-pregnancy group $7 \mathrm{~min}$ following fentanyl administration $(1.35 \% / \mathrm{min})$ was significantly faster than that in the time-matched early pregnancy group $(0.71 \% / \mathrm{min})$ and postpartum group $(0.66 \% / \mathrm{min})$ (Figure $3 \mathrm{D})$. Similar results were observed at $8 \mathrm{~min}$ (Table 3B and Figure 3D).

Table 3B Decrease rate of $\mathrm{SpO}_{2}(\% / \mathrm{min})$ among three groups

\begin{tabular}{llll}
\hline Time & $\begin{array}{l}\text { Non-pregnancy } \\
(\mathbf{n}=\mathbf{2 0})\end{array}$ & $\begin{array}{l}\text { Early pregnancy } \\
(\mathbf{n}=\mathbf{2 0})\end{array}$ & $\begin{array}{l}\text { Postpartum } \\
(\mathbf{n}=\mathbf{2 0})\end{array}$ \\
\hline $6 \mathrm{~min}$ & $1.36 \pm 0.35$ & $0.71 \pm 0.43^{*}$ & $0.66 \pm 0.26^{*}$ \\
$8 \mathrm{~min}$ & $1.21 \pm 0.34$ & $0.53 \pm 0.24^{*}$ & $0.53 \pm 0.25^{*}$ \\
\hline
\end{tabular}

Note: $* P<0.01$ (vs non-pregnancy group).

Abbreviation: $\mathrm{SpO}_{2}$, pulse oxygen saturation.
We also compared $\mathrm{SpO}_{2}$ levels in the three groups at each measured time point. $\mathrm{SpO}_{2}$ levels were significantly higher in the early pregnancy group compared to the other groups at almost all the time points following fentanyl administration (Table 3A and Figure 3E). The postpartum group showed significantly higher $\mathrm{SpO}_{2}$ levels at 5 and $10 \mathrm{~min}$ compared with the time-matched non-pregnancy group measurements (5 min: $93.65 \% \pm 2.60 \%$ vs $89.20 \% \pm 3.68 \%$; 10 min: $93.30 \% \pm 2.11 \%$ vs $88.85 \% \pm 1.66 \%$ ) (Table $3 \mathrm{~A}$ and Figure 3E).

\section{Lowest $\mathrm{SpO}_{2}$ levels correlate positively with plasma progesterone levels following fentanyl treatment}

Progesterone is an essential hormone to maintain pregnancy and functions in regulating the respiratory response. ${ }^{1,2}$ Thus, we examined the relationship between progesterone levels in plasma and the lowest $\mathrm{SpO}_{2}$ levels in the three groups following fentanyl treatment (Table 4). As shown in Figure 4A, progesterone levels were $96.01 \pm 0.68 \mathrm{nmol} / \mathrm{L}$ in the early pregnancy group and $8.26 \pm 0.45 \mathrm{nmol} / \mathrm{L}$ in the postpartum group, which were significantly higher than that 
Table 4 Lowest $\mathrm{SpO}_{2}$ and progesterone level among three groups

\begin{tabular}{llll}
\hline & $\begin{array}{l}\text { Non-pregnancy } \\
(\mathbf{n}=\mathbf{2 0})\end{array}$ & $\begin{array}{l}\text { Early pregnancy } \\
(\mathbf{n}=\mathbf{2 0})\end{array}$ & $\begin{array}{l}\text { Postpartum } \\
(\mathbf{n}=\mathbf{2 0})\end{array}$ \\
\hline Lowest $\mathrm{SPO}_{2}(\%)$ & $85.90 \pm 2.73$ & $92.55 \pm 3.03^{*}$ & $91.75 \pm 2.00^{*}$ \\
Progesterone & $2.45 \pm 1.91$ & $96.01 \pm 29.07^{*}$ & $8.26 \pm 3.50^{\#}$ \\
level (nmol/L) & & & \\
\hline
\end{tabular}

Note: $* P<0.01$ (vs non-pregnancy group) and $\# P<0.05$ (vs early pregnancy group). Abbreviation: $\mathrm{SpO}_{2}$, pulse oxygen saturation.

in the non-pregnancy control group $(2.45 \pm 0.61 \mathrm{nmol} / \mathrm{L})$. Similarly, the lowest $\mathrm{SpO}_{2}$ levels in early pregnancy and postpartum groups were significantly higher than the nonpregnancy control group (Figure 4B).

To determine whether progesterone content affects $\mathrm{SpO}_{2}$ following fentanyl administration, we analyzed the correlation between plasma progesterone contents and the lowest $\mathrm{SpO}_{2}$ levels in all patients of three groups. As shown in Figure $4 \mathrm{C}$, the lowest $\mathrm{SpO}_{2}$ levels after intravenous fentanyl showed a positive correlation with plasma progesterone levels $\left(y=0.049 x+88.31, R^{2}=0.332, P<0.01\right)$.

\section{Discussion}

Postoperative pain is a fundamental issue in clinics. Of all the contemporary analgesics, opioids are the most potent analgesic drugs. However, the side effect of respiratory depression induced by opioids is a concern for anesthesiologists and limits the use of opioids in the postoperative analgesia. ${ }^{2}$ The present data demonstrate that the intravenous fentanyl-induced respiratory depression is improved in early pregnancy and postpartum patients compared with non-pregnant patients, with improvement being positively correlated with plasma progesterone level.

Opioid-induced respiratory depression following postoperative analgesia is related to various factors, including the type of the drug, dosage, rate of infusion, type of surgery and patient age and gender. This respiratory depression has rarely been found in the setting of obstetric analgesia. ${ }^{3}$ The mechanism for this phenomenon is still unclear. Presently, we observed the changes in the respiratory parameters after intravenous fentanyl use in patients with different pregnancy status to investigate the effect of pregnancy on respiratory response to intravenous fentanyl. The early pregnancy group comprised women with high level of progesterone because of pregnancy, the postpartum group included women with a medium level of progesterone due to placental remnants and the control group included women who were not pregnant with a low level of progesterone.
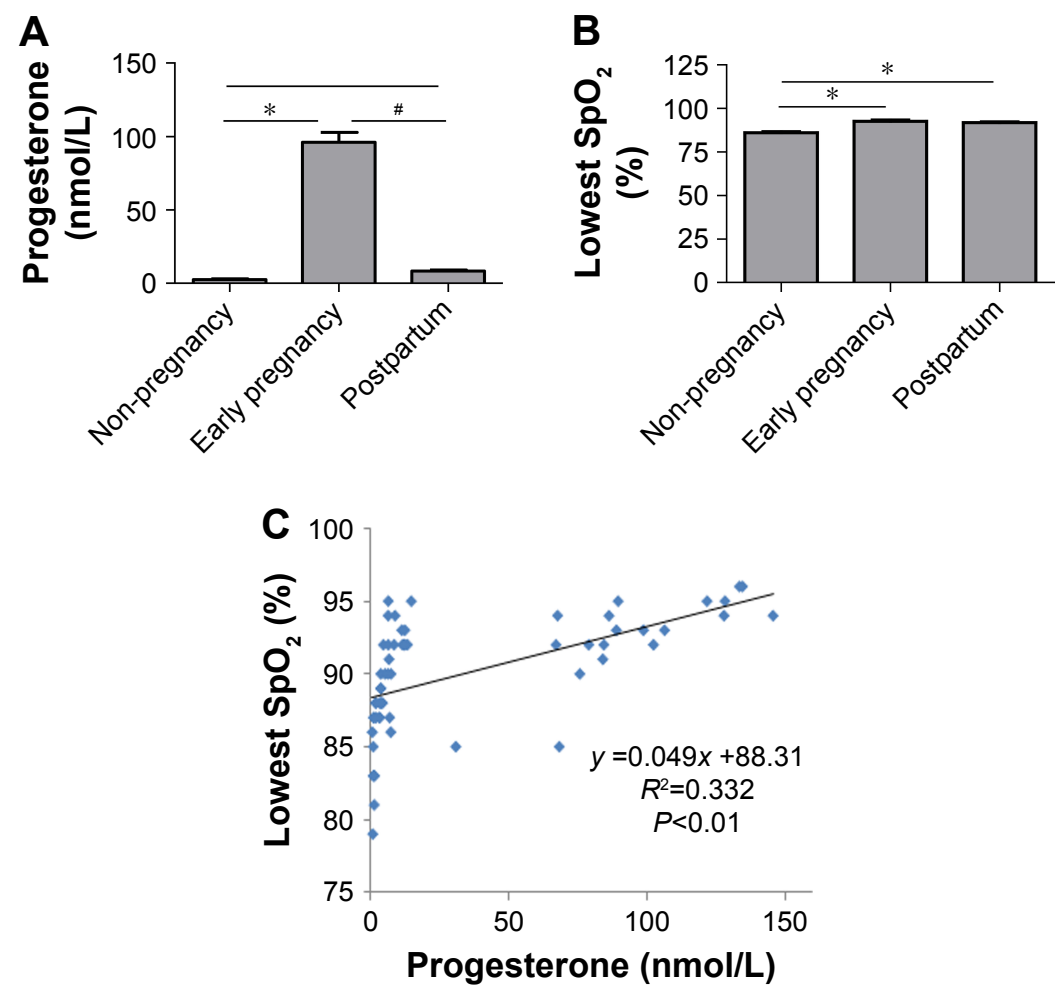

Figure 4 The lowest $\mathrm{SpO}_{2}$ demonstrated a positive correlation with the levels of plasma progesterone following fentanyl treatment.

Notes: (A) Levels of plasma progesterone were measured in three groups of patients. Blood was sampled just before fentanyl infusion. ${ }^{\# P}<0.05$ and $* P<0.01, n=20$ per group. (B) The lowest levels of $\mathrm{SpO}_{2}$ were shown in all three groups. $* \mathrm{P}<0.0 \mathrm{I}, \mathrm{n}=20$ per group. (C) Correlation of the lowest levels of $\mathrm{SpO}$ and plasma progesterone levels. The measurements contained 60 samples.

Abbreviation: $\mathrm{SpO}_{2}$, pulse oxygen saturation. 
Intravenous injection of fentanyl $2 \mu \mathrm{g} / \mathrm{kg}$ at a rate of $1 \mathrm{~mL}$ every $3 \mathrm{~s}$ was reported to be a good model to observe the effect of fentanyl on ventilatory response. ${ }^{4}$ In this study, we observed that, after intravenous infusion of $2 \mu \mathrm{g} / \mathrm{kg}$ fentanyl, patients of the early pregnancy group and postpartum group had less respiratory depression, compared with those in the non-pregnancy control group. Only one patient in the control group had a temporary hypoxemia with the $\mathrm{SpO}_{2}$ marginally $<80 \%$ (79\%). The patient recovered after being reminded to take a deep breath.

There was no significant difference in the baseline $\mathrm{P}_{\mathrm{ET}} \mathrm{CO}_{2}$ level between the early pregnancy group and the postpartum group. However, the baseline level of the $\mathrm{P}_{\mathrm{ET}} \mathrm{CO}_{2}$ in the control patients was significantly higher than that in early pregnancy and postpartum patients. Following fentanyl infusion, the values of $\mathrm{P}_{\mathrm{ET}} \mathrm{CO}_{2}$ increased rapidly in all the three groups of patients. However, the increased rate was significantly more rapid in the control group. Moreover, $\mathrm{P}_{\mathrm{ET}} \mathrm{CO}_{2}$ values at 1,3 , 10 , and 15 min following fentanyl infusion were significantly increased in control patients. The data suggest that pregnancy attenuates the fentanyl-induced increase in $\mathrm{P}_{\mathrm{ET}} \mathrm{CO}_{2}$.

The levels of $\mathrm{SpO}_{2}$ were decreased immediately after fentanyl infusion, with a significantly slower subsequent rate of decrease in the early pregnancy and postpartum groups than that in the control group. Interestingly, there was a significantly higher level of $\mathrm{SpO}_{2}$ in the early pregnancy group both at baseline and after fentanyl administration. The data suggest an effect of pregnancy on $\mathrm{SpO}_{2}$ decrease in fentanyl-treated patients. After the intravenous fentanyl injection, hyperventilation during pregnancy may at least partially alleviate the respiratory depressive effects of opioids. Jensen et $\mathrm{al}^{1}$ reported that the pregnancy-induced hyperventilation and the accompanied hypocapnia were the result of pregnancy-induced changes of the respiratory function, acid-base balance, metabolism, and cerebral blood flow. Of note, progesterone increases the alveolar ventilation of the women in pregnancy and luteal phase ${ }^{5}$ and has been successfully used in the treatment of sleep apnea syndrome. ${ }^{6}$ Comparison of women at 20 weeks post-partum demonstrated that women in the third trimester of pregnancy had lower progesterone, estradiol, and intravenous $\mathrm{CO}_{2}$ levels, but the change of the $\mathrm{CO}_{2}$ was not related to the levels of progesterone and estradiol, ${ }^{1,7}$ which is consistent with our study. But, we found the lowest $\mathrm{SpO}_{2}$ of all patients after the fentanyl injection was significantly correlated with their progesterone levels.

Attenuated respiratory depression observed in the women during 45-60 days of gestation and 5-7 days postpartum is possibly related to the pregnancy-induced decrease of the response to opioids. The locus coeruleus (LC) principally regulates the body dependence on opioids. Morphine and enkephalin can inhibit the discharge of LC. In animals with morphine tolerance, LC discharge is also tolerated. ${ }^{8}$ Compared with the non-pregnant rats, rats at the end of pregnancy reportedly display increased endogenous enkephalin and $\mu$-receptor in the nucleus tractus solitarius, resulting in release of presynaptic norepinephrine, inhibition of corticotrophin-releasing hormone, and activity of the hypothalamic-pituitary-adrenal axis. ${ }^{9}$ This series of reactions may be related to the metabolism of progesterone to allopregnanolone, which can induce the expression of enkephalin-A mRNA in the nucleus tractus solitarius (NTS) of non-pregnant or late-pregnant rats. ${ }^{10}$ Thus, it is possible that the pregnancy-induced increase in endogenous opioids like enkephalin can inhibit the function of the nucleus and cause the increase of the opioid receptors or even result in tolerance, which leads to less potency of the exogenous opioids and less opioidinduced respiratory depression. This may be related to the progesterone level. The reduced anesthetic requirements for women in the luteal phase ${ }^{11}$ may be interpreted as the above reasons, but the exact mechanism remains to be clarified further.

There are some limitations of the study. First, the sample size is not large. This could limit the power of the statistical analysis. Multicenter clinical trials should be done to confirm the correlation found presently. Second, we did not monitor arterial carbon dioxide concentrations to assess respiratory depression. Instead, we used $\mathrm{RR}$ and $\mathrm{P}_{\mathrm{ET}} \mathrm{CO}_{2}$ levels, because they could be monitored in real-time and their dynamic change could be easily measured. As well, the $\mathrm{P}_{\mathrm{ET}} \mathrm{CO}_{2}$ could indirectly reflect arterial carbon dioxide concentrations. Third, we did not recruit late pregnancy patients because fentanyl is rarely used in this setting. Instead, we chose the patients with placental remnants scheduled for complete curettage. Although many of the physiological changes of pregnancy would have changed at this stage, these patients could still have relatively high levels of progesterone. More studies recruiting different trimesters of pregnant patients with proper sample size and more accurate monitoring indicators should be carried out.

\section{Conclusion}

Pregnancy can attenuate the respiratory depression induced by intravenous fentanyl injection, which may be related to increased progesterone level. 


\section{Acknowledgment}

This research did not receive any specific grant from funding agencies in the public, commercial, or not-for-profit sectors.

\section{Disclosure}

The authors report no conflicts of interest in this work.

\section{References}

1. Jensen D, Duffin J, Lam YM, et al. Physiological mechanisms of hyperventilation during human pregnancy. Respir Physiol Neurobiol. 2008;161(1):76-86.

2. Roozekrans M, van der Schrier R, Okkerse P, Hay J, McLeod JF, Dahan A. Two studies on reversal of opioid-induced respiratory depression by BK-channel blocker GAL021 in human volunteers. Anesthesiology. 2014;121(3):459-468.

3. Carvalho B. Respiratory depression after neuraxial opioids in the obstetric setting. Anesth Analg. 2008;107(3):956-961.

4. Dahan A, Roozekrans M, van der Schrier R, Smith T, Aarts L. Primum non nocere or how to resolve drug-induced respiratory depression. Anesthesiology. 2013;118(6):1261-1263.
5. Kimura H, Tatsumi K, Kunitomo F, et al. Obese patients with sleep apnea syndrome treated by progesterone. Tohoku J Exp Med. 1988; 156(suppl):151-157.

6. Andersen ML, Bittencourt LR, Antunes IB, Tufik S. Effects of progesterone on sleep: a possible pharmacological treatment for sleepbreathing disorders. Curr Med Chem. 2006;13(29):3575-3582.

7. Jensen D, Webb KA, Davies GA, O'Donnell DE. Mechanisms of activity-related breathlessness in healthy human pregnancy. Eur J Appl Physiol. 2009;106(2):253-265.

8. Guajardo HM, Snyder K, Ho A, Valentino RJ. Sex differences in $\mu$-opioid receptor regulation of the rat locus coeruleus and their cognitive consequences. Neuropsychopharmacology. 2017;42(6):1295-1304.

9. Brunton PJ, Russell JA. Attenuated hypothalamo-pituitary-adrenal axis responses to immune challenge during pregnancy: the neurosteroid opioid connection. J Physiol. 2008;586(2):369-375.

10. Brunton PJ, Meddle SL, Ma S, Ochedalski T, Douglas AJ, Russell JA. Endogenous opioids and attenuated hypothalamic-pituitary-adrenal axis responses to immune challenge in pregnant rats. J Neurosci. 2005; 25(21):5117-5126.

11. Erden V, Yangin Z, Erkalp K, Delatioğlu H, Bahçeci F, Seyhan A. Increased progesterone production during the luteal phase of menstruation may decrease anesthetic requirement. Anesth Analg. 2005;101(4): 1007-1011. table of contents.

\section{Publish your work in this journal}

Drug Design, Development and Therapy is an international, peerreviewed open-access journal that spans the spectrum of drug design and development through to clinical applications. Clinical outcomes, patient safety, and programs for the development and effective, safe, and sustained use of medicines are the features of the journal, which has also been accepted for indexing on PubMed Central. The manuscript management system is completely online and includes a very quick and fair peer-review system, which is all easy to use. Visit $\mathrm{http}: / /$ www.dovepress.com/testimonials.php to read real quotes from published authors. 